\title{
The evidence base for circulating tumour DNA blood-based biomarkers for the early detection of cancer: a systematic mapping review
}

Ian A. Cree ${ }^{1,2,3^{*}}$, Lesley Uttley ${ }^{4}$, Helen Buckley Woods ${ }^{4}$, Hugh Kikuchi ${ }^{5}$, Anne Reiman ${ }^{2}$, Susan Harnan ${ }^{4}$, Becky L. Whiteman ${ }^{6}$, Sian Taylor Philips ${ }^{7}$, Michael Messenger ${ }^{8}$, Angela Cox ${ }^{9}$, Dawn Teare ${ }^{4}$, Orla Sheils ${ }^{10}$, Jacqui Shaw ${ }^{11}$ and For the UK Early Cancer Detection Consortium

\begin{abstract}
Background: The presence of circulating cell-free DNA from tumours in blood (ctDNA) is of major importance to those interested in early cancer detection, as well as to those wishing to monitor tumour progression or diagnose the presence of activating mutations to guide treatment. In 2014, the UK Early Cancer Detection Consortium undertook a systematic mapping review of the literature to identify blood-based biomarkers with potential for the development of a non-invasive blood test for cancer screening, and which identified this as a major area of interest. This review builds on the mapping review to expand the ctDNA dataset to examine the best options for the detection of multiple cancer types.

Methods: The original mapping review was based on comprehensive searches of the electronic databases Medline, Embase, CINAHL, the Cochrane library, and Biosis to obtain relevant literature on blood-based biomarkers for cancer detection in humans (PROSPERO no. CRD42014010827). The abstracts for each paper were reviewed to determine whether validation data were reported, and then examined in full. Publications concentrating on monitoring of disease burden or mutations were excluded.

Results: The search identified 94 ctDNA studies meeting the criteria for review. All but 5 studies examined one cancer type, with breast, colorectal and lung cancers representing 60\% of studies. The size and design of the studies varied widely. Controls were included in 77\% of publications. The largest study included 640 patients, but the median study size was 65 cases and 35 controls, and the bulk of studies (71\%) included less than 100 patients. Studies either estimated cfDNA levels non-specifically or tested for cancer-specific mutations or methylation changes (the majority using PCR-based methods).

Conclusion: We have systematically reviewed ctDNA blood biomarkers for the early detection of cancer. Preanalytical, analytical, and post-analytical considerations were identified which need to be addressed before such biomarkers enter clinical practice. The value of small studies with no comparison between methods, or even the inclusion of controls is highly questionable, and larger validation studies will be required before such methods can be considered for early cancer detection.
\end{abstract}

Keywords: cfDNA, ctDNA, Cancer, Detection, Diagnosis, Liquid biopsy

\footnotetext{
* Correspondence: creei@iarc.fr

${ }^{1}$ WHO Classification of Tumours Group, International Agency for Research on

Cancer (IARC), World Health Organization, 150 Cours Albert Thomas, 69372

Lyon, CEDEX 08, France

${ }^{2}$ Faculty of Health and Life Sciences, Coventry University, Priory Street,

Coventry CV1 5FB, UK

Full list of author information is available at the end of the article
} 


\section{Background}

The early detection of cancers before they metastasise to other organs allows definitive local treatment, resulting in excellent survival rates. This is particularly true for breast cancer, but also others, including lung and colorectal cancer [1]. Early detection and diagnosis has therefore been a major goal of cancer research for many years, and the concept of early detection from a blood sample has been the focus of considerable effort. However, to date no blood biomarkers have had sufficient sensitivity and specificity to warrant their clinical use for early cancer detection, and their potential remains unrealised [2]. Hanahan and Weinberg [3] identified the major biological attributes of cancer, and it is apparent that most if not all of these biological processes give rise to biomarkers present in blood [4]. Circulating cell free DNA produced from cancers is known as circulating tumour DNA (ctDNA), and represents a subset of the circulating DNA (cfDNA) normally present at low levels in the blood of healthy individuals.

Since the first description of circulating cfDNA in blood $[5,6]$, it has become clear that total ctDNA levels rise in a number of disorders in addition to cancer including myocardial infarction [7], serious infections, and inflammatory conditions [8], as well as pregnancy where it can be used for prenatal diagnosis [9]. The source of this DNA appears to be mainly the result of cell death either by necrosis or apoptosis [5, 9-11]. A raised ctDNA level is therefore non-specific, but may indicate the presence of serious disease. In blood, ctDNA is always present as small fragments, which makes assay design challenging [12]. Nevertheless, many analytical methods are available to measure ctDNA, and the field is rapidly maturing to the point where it may be clinically relevant to many patients.

In 2014, the UK Early Cancer Detection Consortium (ECDC) conducted a rapid mapping review of blood biomarkers of potential interest for cancer screening [13], and identified 814 biomarkers, including 39 ctDNA biomarkers. This paper uses the list generated from the mapping review, updated with relevant publications published since its completion to discuss the candidacy of ctDNA markers for early detection of cancer.

\section{Methods}

Our mapping review [13] conducted comprehensive searches of the electronic databases Medline, Embase, CINAHL, the Cochrane library, and Biosis to obtain relevant literature on blood-based biomarkers for cancer detection in humans (PROSPERO no. CRD42014010827). The search period finished in July 2014, therefore the searches have been updated to December 2016 using the same search terms. The abstracts of the publications retrieved were reviewed to identify those with validation data (usually indicated by case-control design) and to determine what ctDNA biomarkers had been measured in serum or plasma. Full details of the methods used are published elsewhere [13], and described briefly here. English language publications of any sample size were eligible and the full eligibility criteria used are provided in Table 1.

The search strategy was deliberately inclusive, using keywords and subject headings as follows, to provide a comprehensive list of those ctDNA candidate biomarkers that had been used to identify cancers from blood samples. The search terms included 'cancer' 'diagnosis', 'markers', 'blood', and 'screening' with 'DNA', 'cfDNA', or 'ctDNA'. Keywords and subject headings were determined by members of the ECDC working with the review team at the University of Sheffield. The results of the searches were collated in an Endnote database and results tabulated, with references, size of study, and methods used. To avoid bias, two reviewers conducted screening; references identified by either as relevant were included for further inspection. Those featuring ctDNA with data related to diagnosis or detection of three or more types of cancer were identified and retained for closer scrutiny to determine their potential utility.

Table 1 Search criteria for ctDNA publications

\begin{tabular}{ll}
\hline Inclusion Criteria & Exclusion Criteria \\
\hline English language studies & Studies published in non-English language \\
Studies within last seven years (2010-2016) & Studies published in 2009 or earlier \\
Controlled studies & Citation titles without abstracts \\
$\begin{array}{ll}\text { Validation Studies (comparison with controls) } & \text { Parallel publications and reviews based on the same } \\
\text { Biomarkers measured in blood plasma or serum } \\
\text { (markers or biomarkers) }\end{array}$ & or overlapping patient populations \\
DNA (including cfDNA and ctDNA) & Prognosis or prediction (treatment response) associated markers \\
Human DNA & Tissue, blood cells, or other bodily fluid samples \\
\hline
\end{tabular}

${ }^{a}$ Reviews and meta-analyses are cited, but not considered as evidence, but studies were included if they appeared to contain new data 


\section{Results}

Following the updated searches and study selection, a total of $84 \mathrm{ctDNA}$ markers were identified from 94 individual publications (Table 2 and Fig. 1).

The ctDNA biomarkers divided naturally into two groups:

I. those with potential specificity for neoplasia (ctDNA - usually mutations or DNA alterations such as methylation), and

II. those designed to measure DNA levels, which may not be specific to neoplasia.

Figure 2 shows the distribution of studies by cancer type, including two publications on amplification [12, 14], and one on clonality [15]. One of the amplification papers looked at HER2 [14], while the other examined multiple targets by NGS [12].

Of the 94 publications included, 72 publications (77\%) were case-control design diagnostic validation studies, and 22 were case series. The size and design of the studies varied widely. The largest study included 640 cancer patients [16]. The median study size was 65 cases, with a mean of 98 cases (range 12-640 cancer patients), indicating that the bulk of studies $(67 / 94,71 \%)$ included $<100$ patients (Fig. 3).

Most publications were focussed on ctDNA in plasma $(n=67)$ rather than serum $(n=25)$ with 2 comparing both. Plasma was used for 38 markers, and serum for 28 markers, and either for 18 markers (Fig. 4). Two comparative studies of serum and plasma were conducted: one for BRAF mutations, and the other for PIK3CA mutations $[17,18]$.

The target of ctDNA studies and the methods used to measure these targets varied considerably (Figs. 5 and 6 respectively). Non-specific total ctDNA levels (quantitation) were usually estimated by size distribution assays based on repeats: LINE1, and ALU were used in 3 [1921] and 6 publications respectively [20-25]. However, some single genes were also used to measure DNA levels - particularly GAPDH in a series of 4 publications on breast cancer [26-29], and hTERT in 4 publications [30-33]. The majority of publications examined gene methylation markers $(n=49)$, though most examined methylation of multiple target genes for a particular tumour type (Fig. 5). Genes commonly mutated in cancer were also markers of interest, namely APC, BRAF, EGFR, HER2, GNAQ, GNA11, KRAS, P53, and PIK3CA. Only one gene, APC, was studied for both methylation and mutation. Few markers were used to identify particular tumour types, but some are particularly likely to occur in certain tumour types. GNAQ and GNA11 mutations have been identified in the plasma of uveal melanoma patients and are rare in other tumour types [34].
Other mutations are not tumour type-specific, and mutations in 6 of the 9 genes listed above were reported in multiple tumour types.

\section{Discussion}

The number of publications on ctDNA is increasing rapidly $[35,36]$, and a recent review emphasises the potential of the field [37]. Most (71\%) are small case control studies with less than 100 patients, and in our view very few studies meet the requirements of analytical validation allowing their use within accredited (ISO:15,189) clinical laboratories, though some may have unpublished commercially-held analytical validation data. The stage and size of the tumours included is variable, and few studies are large enough to give robust subgroup assessments. Larger tumours produce more ctDNA, though tumour type also has an impact [16]. The value of small studies with no comparison between methods, or even the inclusion of controls is highly questionable. Most include a statement that 'larger studies are required', but larger trials rarely result due to the necessary cost implications. Unless well-designed prospective studies based on sample size calculations are performed, there is little likelihood of such methods reaching clinical practice for the detection of cancer at an early stage. There is also a likelihood of bias in that negative results for these markers are rarely if ever reported, and unlike clinical trials, there is no requirement for the registration of diagnostic validation studies. The use of ctDNA for early cancer detection comes under existing molecular pathology guidance, which emphasises the requirements for careful pre-analytical preparation, analysis, and reporting of results [38]. It is important that studies adhere to the Standards for Reporting of Diagnostic Accuracy Studies (STARD) guidance [39], and regional guidance (e.g. US Food and Drug Adminstration (FDA); UK National Institute for Health and Care Excellence (NICE); Clinical \& Laboratory Standards Institute (CLSI)). It is hardly surprising then that, to date, no ctDNA markers have made it into screening programmes, due in part to the economic feasibility of completing the necessary stages of validation [40]. Nevertheless, there is encouraging evidence that ctDNA can be used to detect cancers of many types [16], and the poor quality of many studies should not detract from this fact.

A plethora of methods are available for ctDNA measurement, which have been well reviewed elsewhere [41]. BEAMing, PCR clamping methods, and deep sequencing using NGS are now the most commonly used [42, 43] and are widely regarded as the most sensitive methods currently available. A recent report of copy number variation $(\mathrm{CNV})$ in breast cancer is not surprising given the ability of this method to detect such changes in pregnancy [15]. However, it should be noted that many of 


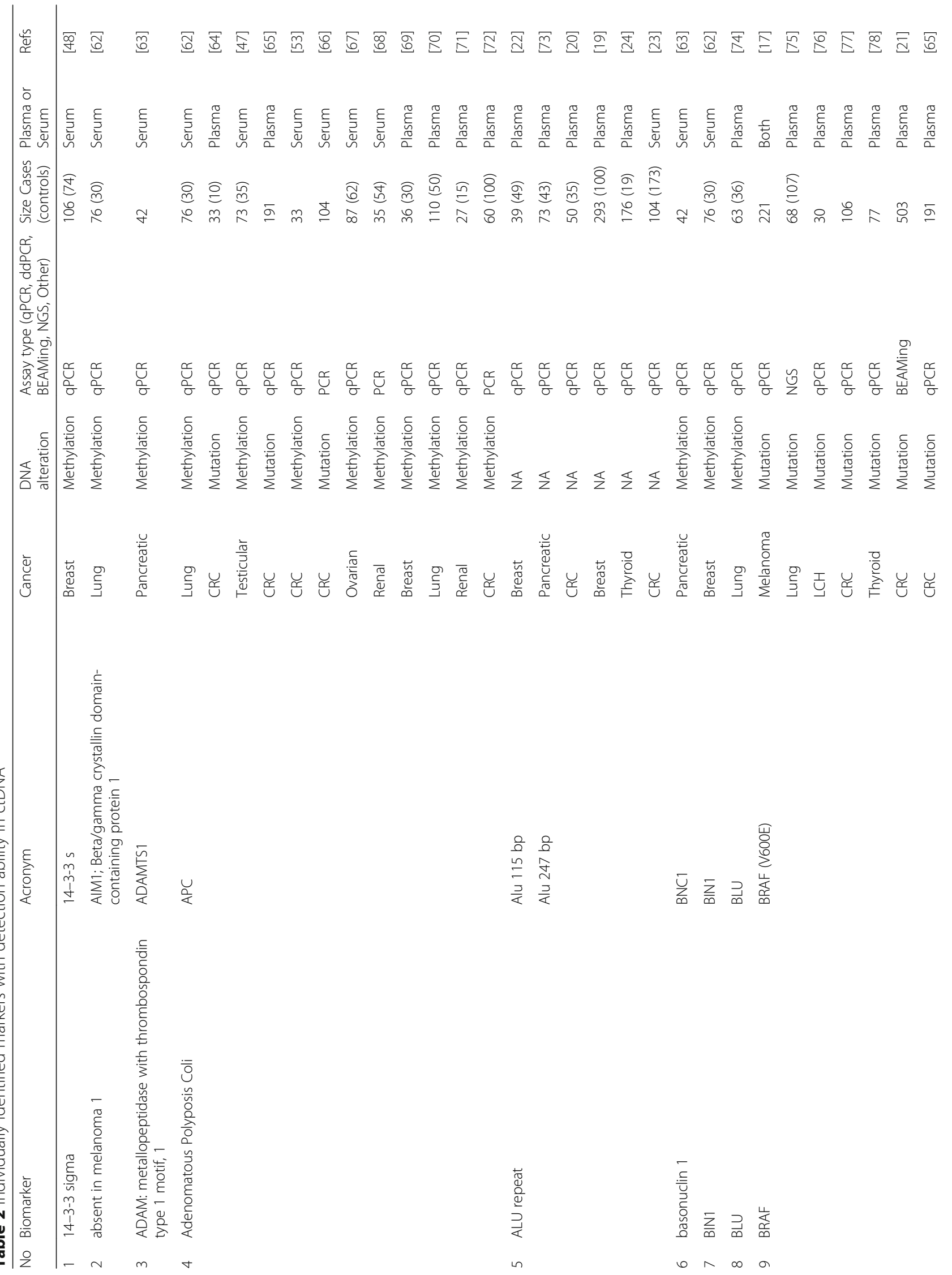




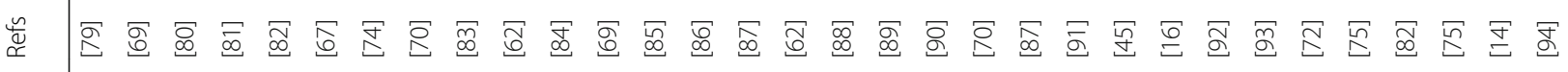

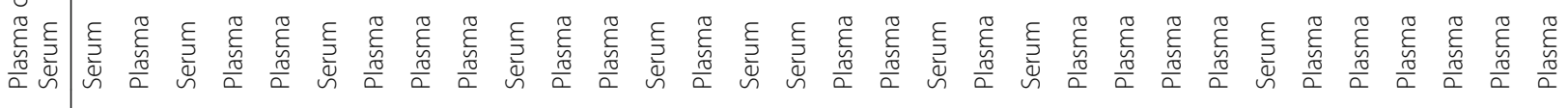

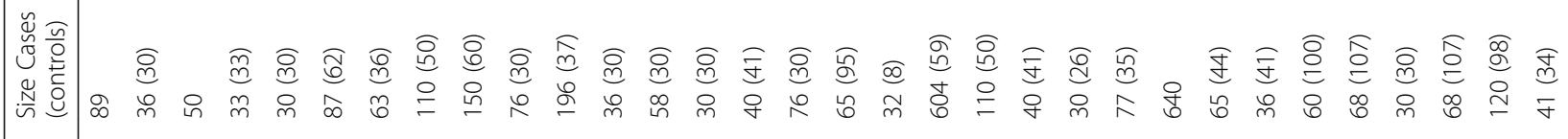
단.

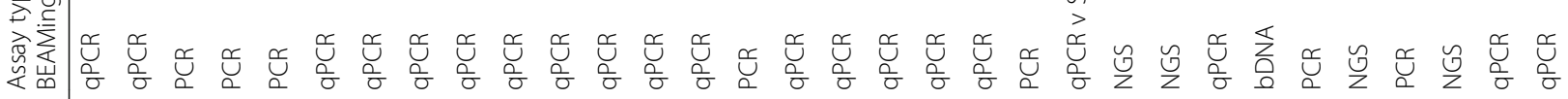

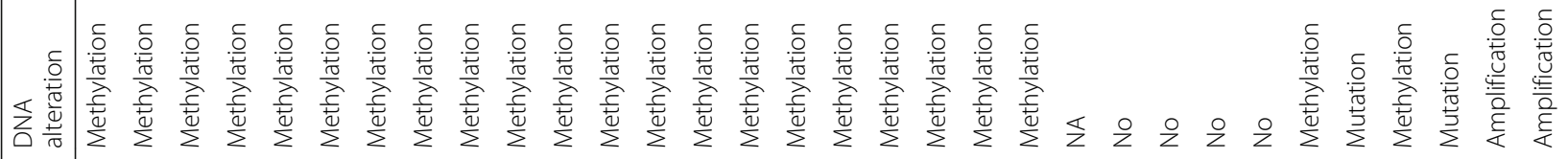

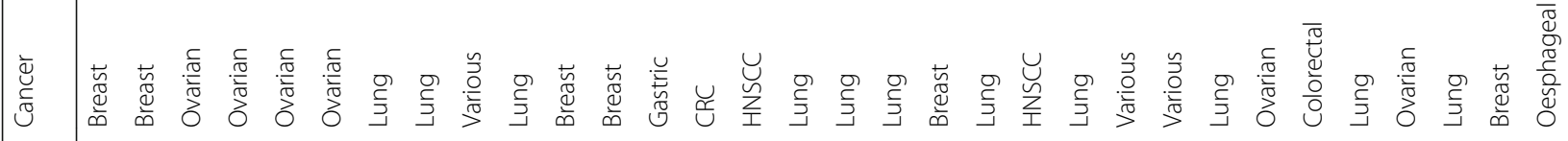




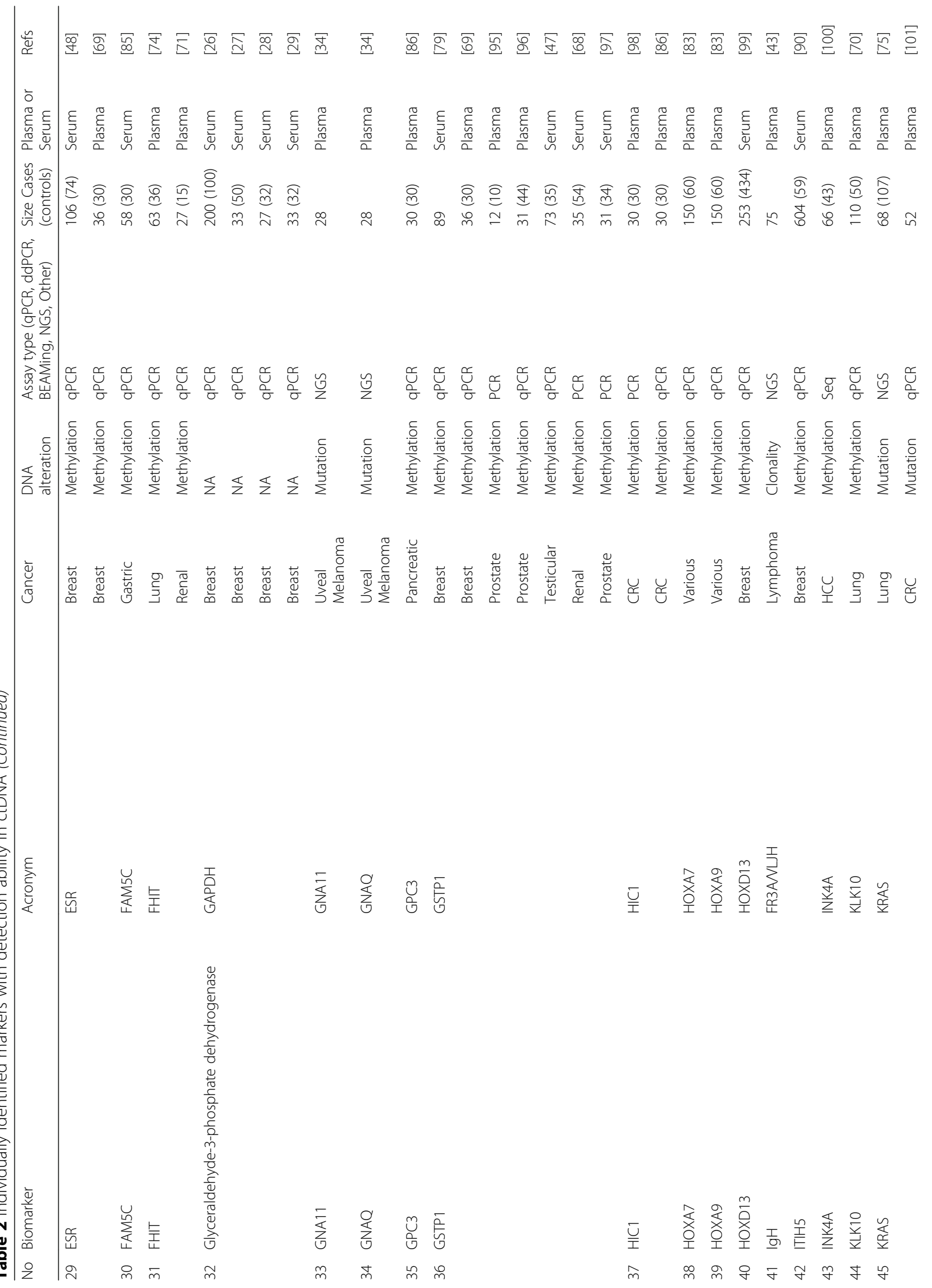




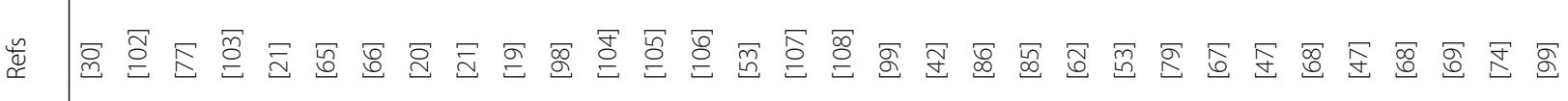

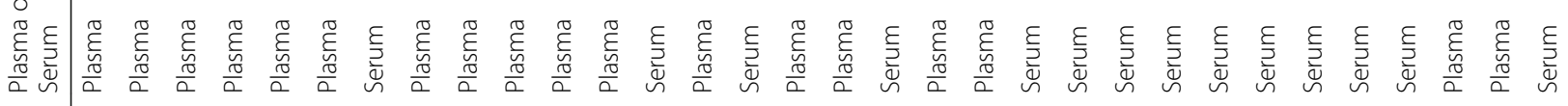

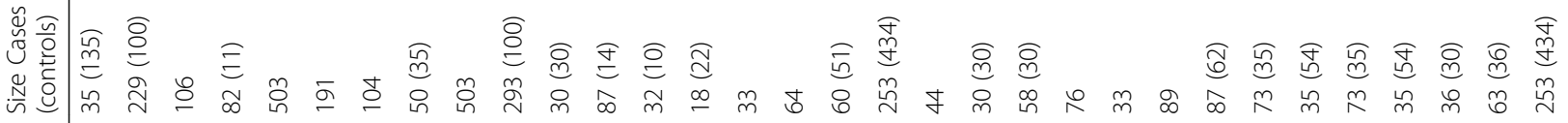 ণ̛

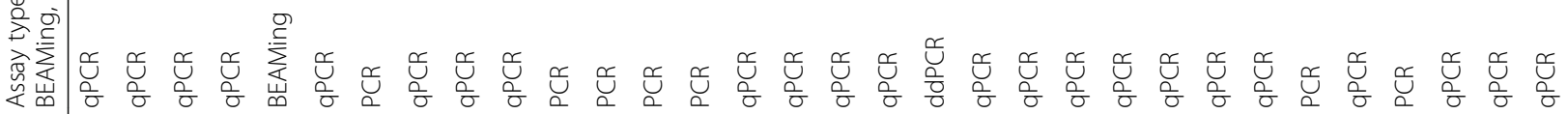

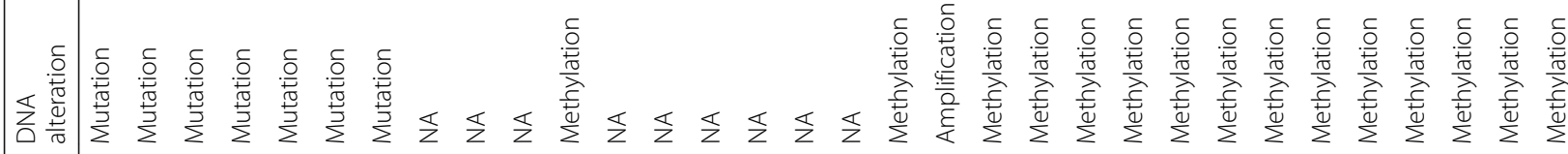 焉}




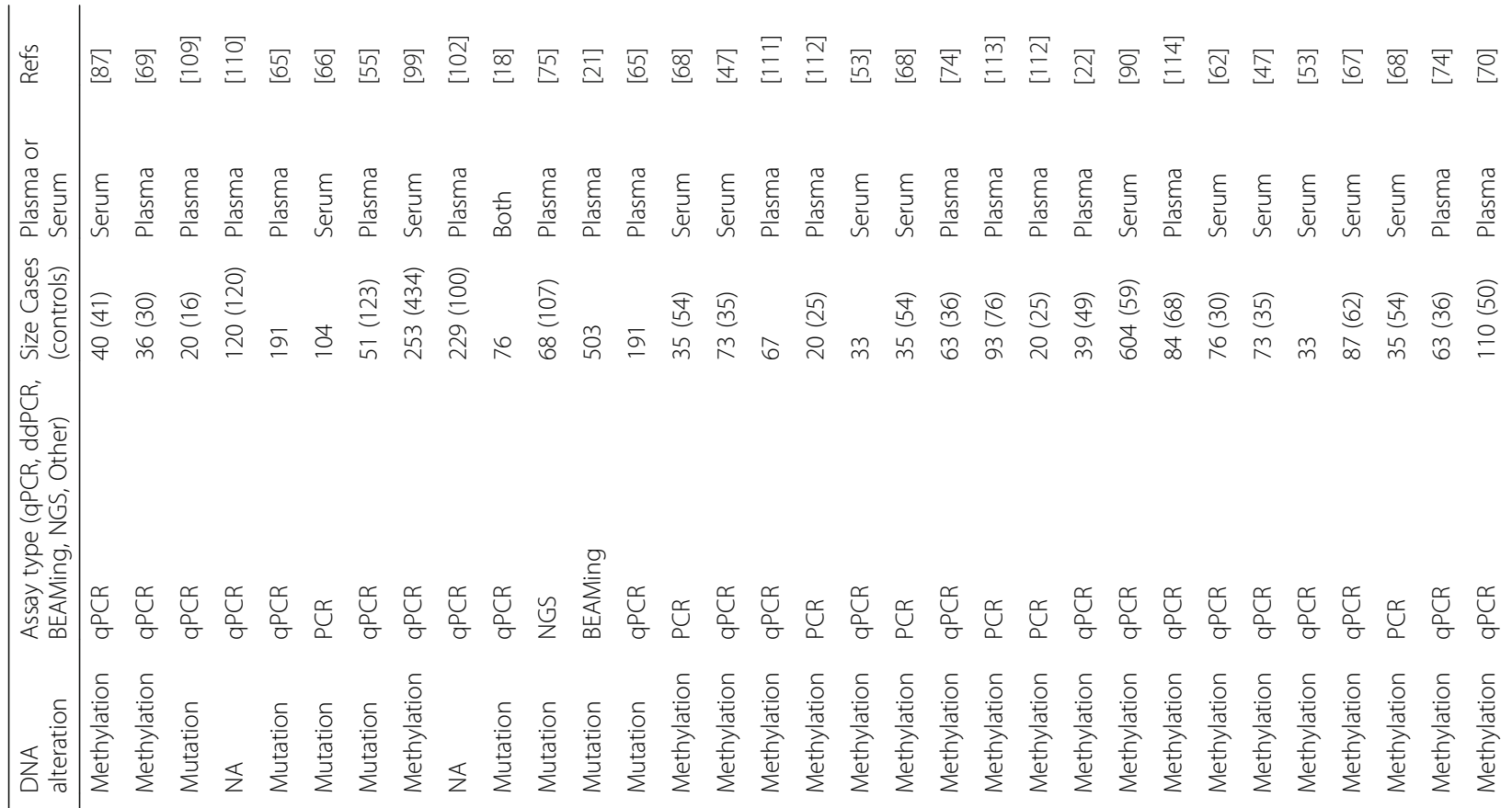

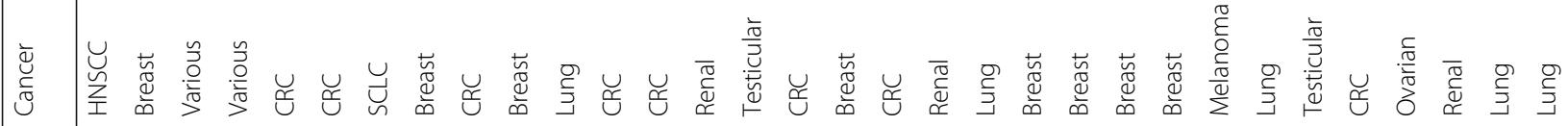
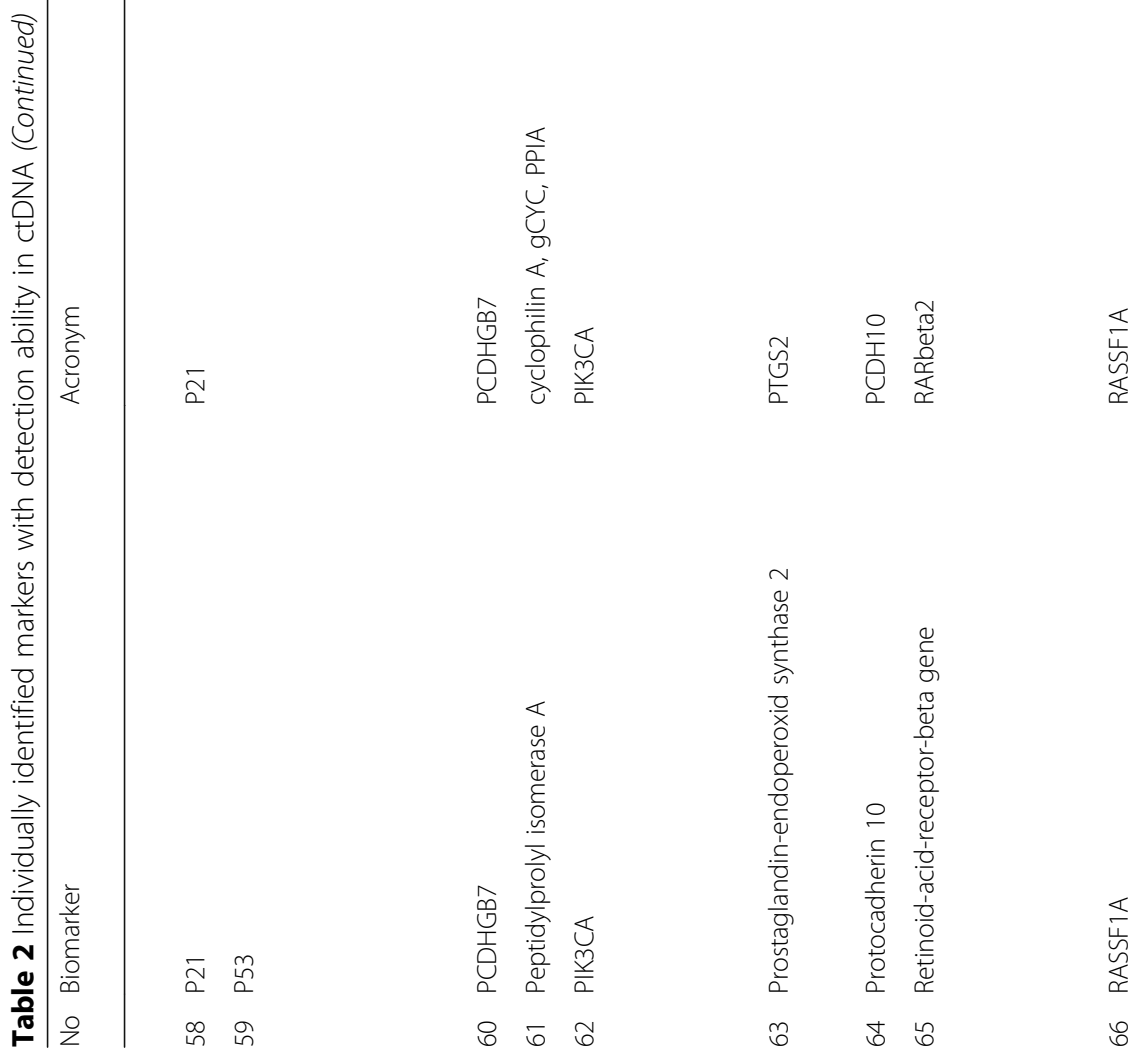


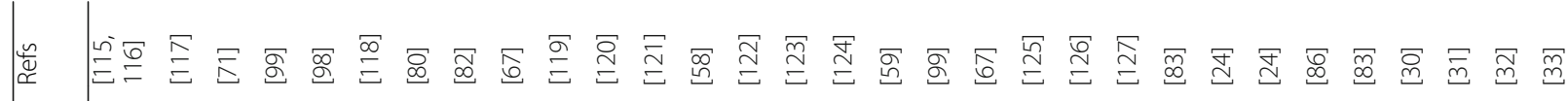

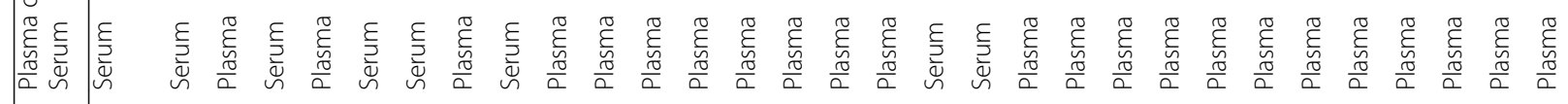

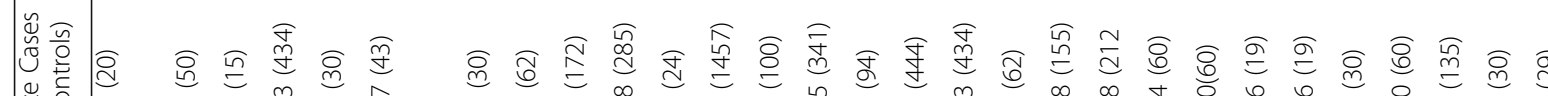

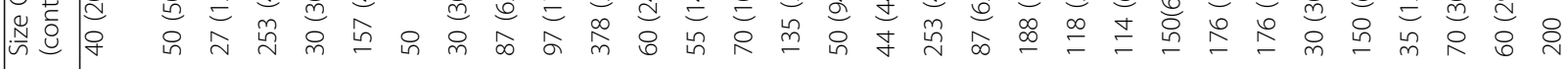
兟

흠 $\overline{\bar{u}}$ वृ 훙

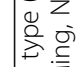

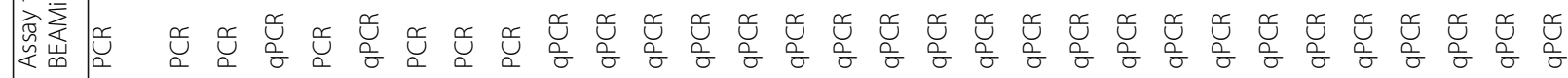

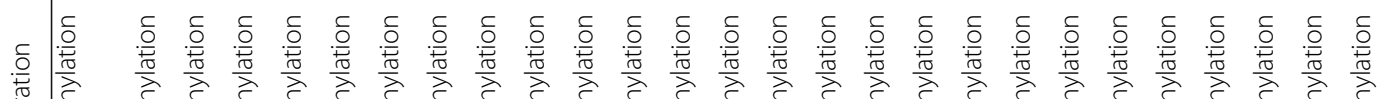

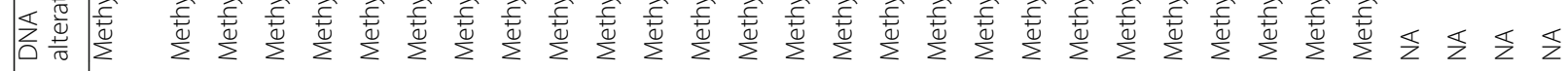

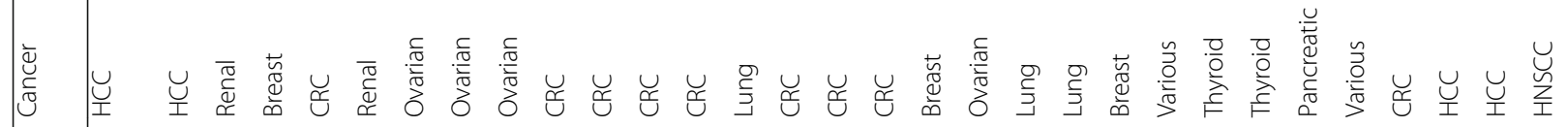

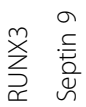

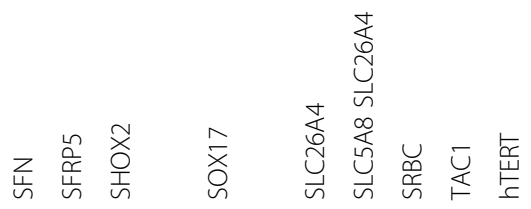




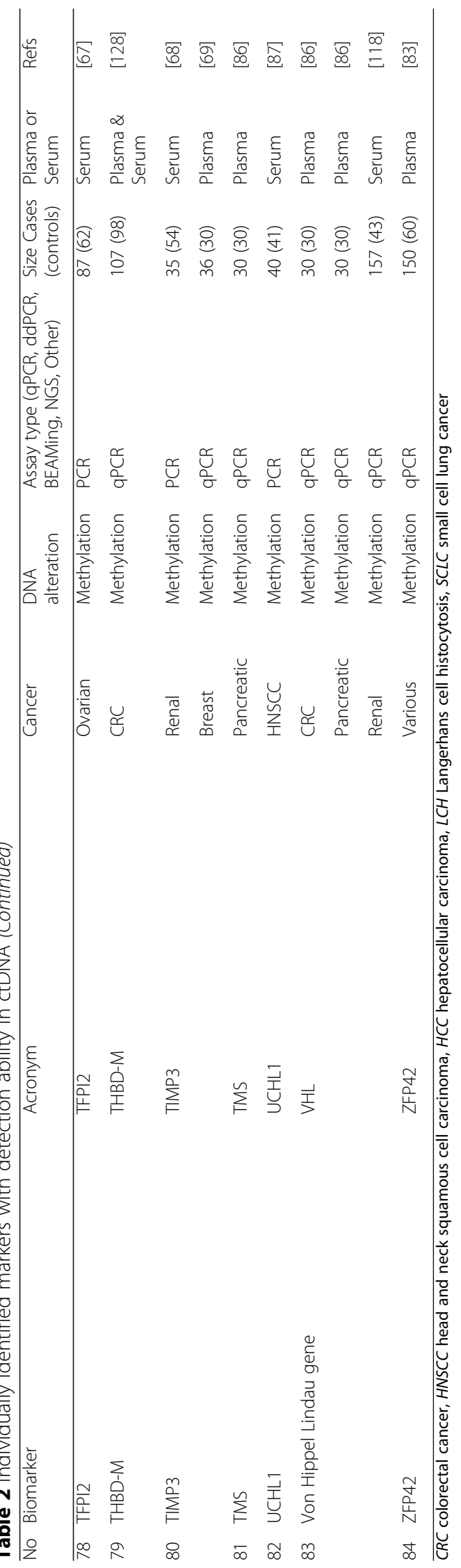




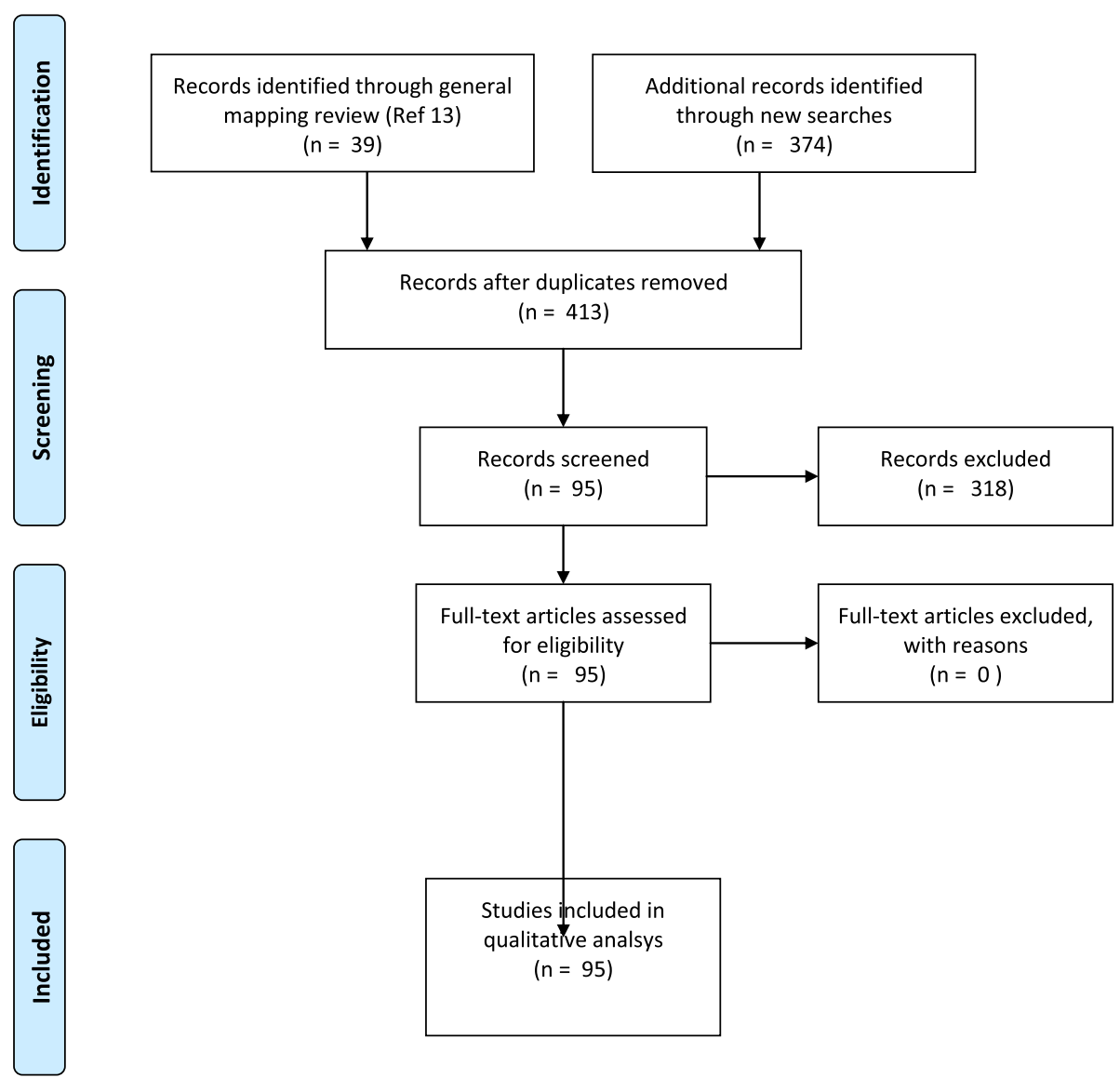

Fig. 1 PRISMA diagram

\section{Tumour Type}

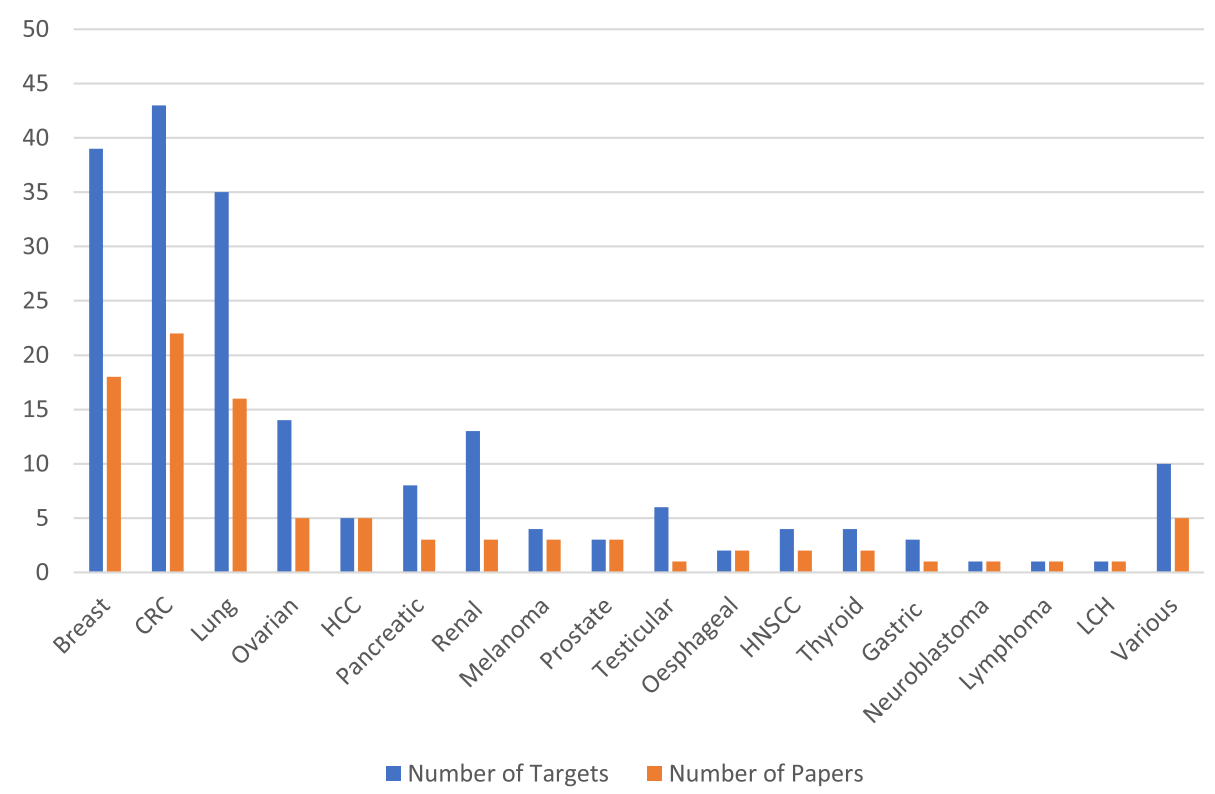

Fig. 2 Number of targets and publications by tumour type, showing the expected concentration of studies on common cancer types. CRC, colorectal cancer; HNSCC, head and neck squamous cell carcinoma; HCC, hepatocellular carcinoma 


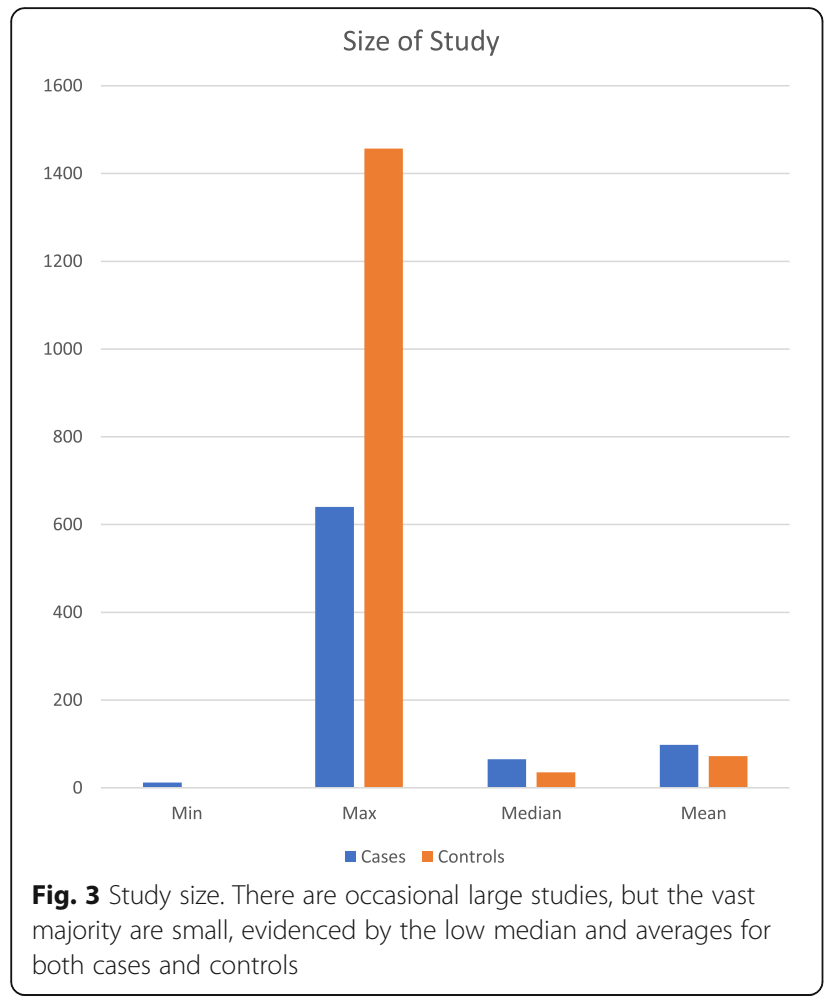

these methods are expensive. The development of highly sensitive NGS methods for ctDNA may prove necessary to obtain the best results [44], but large blood samples (> $10 \mathrm{ml}$ may be needed as the number of DNA molecules present in small samples is often low) [45]. This may be at odds with the key requirement of cost effectiveness for screening programmes, and in our view this represents a real challenge for ctDNA. The problem is probably not insuperable if automation allows the integration of such methods into large blood sciences laboratories, but this is not as yet the case.

As ctDNA is composed largely of short fragments, short amplicons are required for maximum sensitivity of

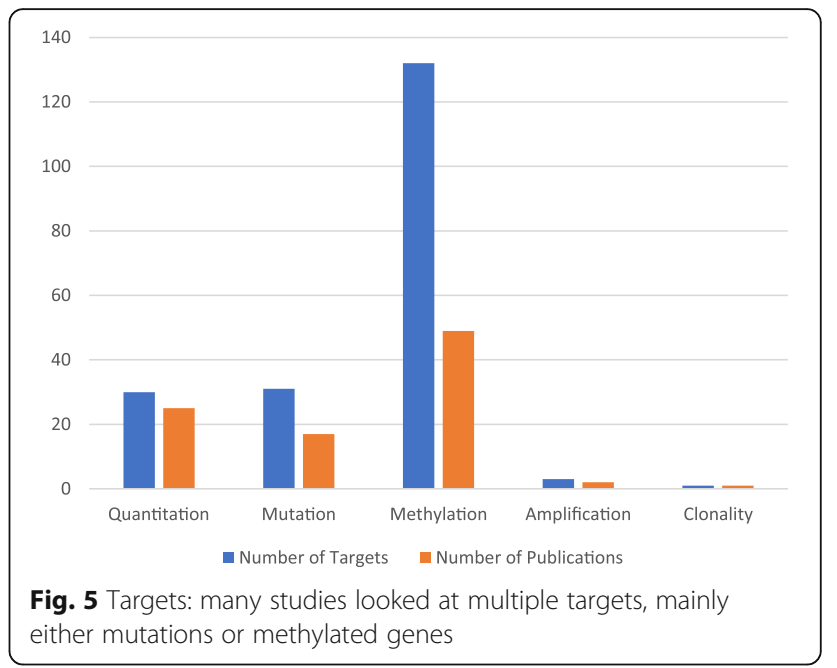

PCR reactions, particularly if mutations are being detected [46]. This is compounded by DNA loss in some reactions, particularly bisulphite modification of DNA, and it may be preferable to use nuclease protection assays $[47,48]$. Methylation of key genes involved in carcinogenesis can be found in ctDNA, and has been studied by many groups, but it should be noted that substantial numbers of normal controls also have methylation of ctDNA for these genes [49].

It is clear that high sensitivity methods will be needed if ctDNA is to be used for early cancer detection. Several factors affect the sensitivity of ctDNA measurement. The first is the extraction method, and there are as yet too few studies which have compared the different options available, which now include automated instruments as well as manual extraction systems $[50,51]$. The proportion of tumour derived DNA (ctDNA) in total cfDNA is greater in plasma than serum, and the higher ctDNA levels in serum are due to leakage from leukocytes during clotting [17]. The dilution effect for ctDNA in serum results in a reduced ability to detect mutations,

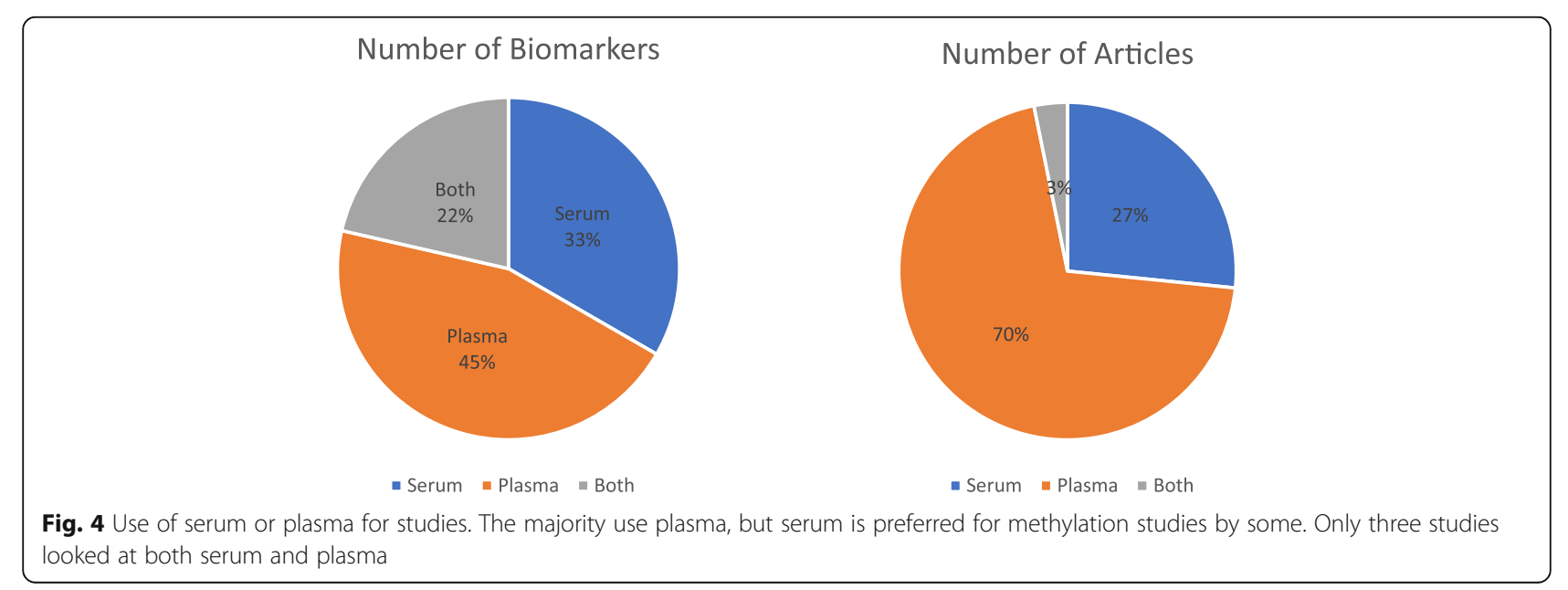




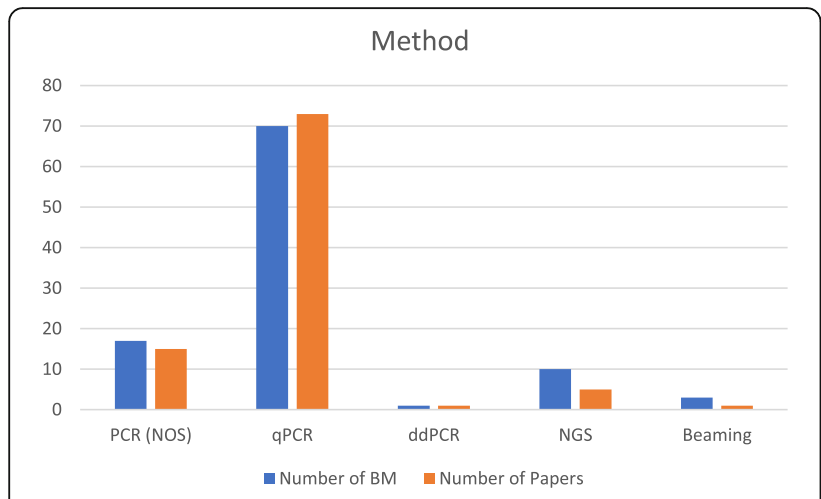

Fig. 6 Choice of method. Most publications used just one method, but biomarkers were measurable by more than one assay in 6 instances

particularly by methods with low analytical sensitivity [50]. Most groups working in the field realise this, and the majority of publications now look at plasma rather than serum.

Several publications were noteworthy, including one influential study which did not include healthy controls [16]. However, the comparison of DNA levels and multiple mutations in plasma from many different tumours types is helpful [44], and makes it clear that some tumours (e.g. gliomas) do not have high ctDNA levels in plasma, as previously found when comparing CSF with plasma [52]. This is also one of several publications that examines early stage disease, and shows that patients with localised disease have lower ctDNA levels [16]. Few publications have examined the ability of ctDNA to detect smaller tumours, though all agree that ctDNA levels increase as tumours enlarge [42].

Choice of target also influences results: the use of LINE1 and ALU repeats allows quantitative size distribution of DNA to be measured. Several publications suggest that this can distinguish cancer, and even precancerous conditions from controls [30]. The size distribution of CRC appears to be different from other tumours due to first pass hepatic metabolism [20,53]. Absolute quantitation by single gene methods such as GAPDH or hTERT will result in lower estimates of DNA content, and it is likely that this is due to the higher sensitivity of the ALU and LINE1 assays [30].

The use of mutations common within cancers is attractive, and the use of ctDNA to provide companion diagnostic information in patients in whom biopsy material is not available is now entering practice [54]. However, it should be noted that such mutations in P53 can occur in the blood of healthy controls, and could give rise to substantial numbers of false positive results [55].

Septin 9 methylation is often regarded as a model for future work [56, 57], and it is notable that there are some large studies [58] within the evidence base for the use of this marker in colorectal cancer, often used in addition to other markers, such as faecal occult blood testing (FoBT) or faecal immunohistochemical testing (FIT). Pre-analytical factors have been examined for this marker [59], including diurnal variation [60]. Plasma methylation of Septin 9 is now available as a commercial test (Epi proColon 2.0; Epigenomics AG, Berlin, Germany) which has recently obtained FDA approval for colorectal cancer screening (April 2016). This is the first blood test to be approved for cancer screening, and represents an encouraging milestone.

Other methylation targets have been studied in depth and show considerable promise. These include APC for colorectal cancer, with a large number of studies (Table 2), and SHOX3, for which a recent meta-analysis suggests that it could have an important role in the diagnosis of lung cancer [61].

There is an encouraging trend towards larger, more ambitious studies, supported by the commercial sector (e.g. (https://clinicaltrials.gov/ct2/show/NCT02889978, and https:/clinicaltrials.gov/ct2/show/NCT03085888). Case control studies (particular retrospective ones) can give biased results, and prospective studies in at-risk cohorts would be more useful in examining the predictive capability of these markers. Such prospective studies should include controls proven not to have cancer. The comparison of new with existing methods (e.g. tumour markers, radiology), and competing technologies, is recommended, and often required by regulators. This has cost implications for funding bodies, but is essential if the field is to progress rapidly.

\section{Conclusions}

While ctDNA analysis may provide a viable option for the early detection of cancers, not all cancers are detectable using current methods. However, improvements in technology are rapidly overcoming some of the issues of analytical sensitivity, and it is likely that mutation and methylation analysis of ctDNA will improve specificity for the diagnosis of cancer.

\section{Abbreviations}

14-3-3 s: 14-3-3 sigma or tyrosine 3-monooxygenase/tryptophan 5monooxygenase activation protein theta; ADAM: metallopeptidase with thrombospondin type 1 motif, 1; AIM1: absent in melanoma 1; ALU: Alu repeat/element 9e; APC: Adenomatous Polyposis Coli; ARF: alternate reading frame; BIN1: bridging integrator 1; BLU: zinc finger MYND-type containing 10; BM: biomarker; BNC1: basonuclin 1; bp: base pair; BRAF: B-Raf protooncogene, serine/threonine kinase; BRCA1: breast cancer 1, DNA repair associated; BRINP3: BMP/Retinoic Acid Inducible Neural Specific 3; CALCA: calcitonin related polypeptide alpha; $\mathrm{CDH1}$ : cadherin 1;

CDH13: cadherin 13; CDO1: cysteine dioxygenase type 1; cfDNA: circulating cell-free DNA; CHD1: chromodomain helicase DNA binding protein 1; CHRM2: cholinergic receptor muscarinic 2; CINAHL: Cumulative Index to Nursing and Allied Health Literature; CLSI: Clinical \& Laboratory Standards Institute; CRC: colorectal carcinoma; CST6: cystatin 6; ctDNA: circulating tumour DNA; CYCD2: cyclin D2; DAPK1: death-associated protein kinase 1; DCC: DCC Netrin 1 receptor; DCLK1: doublecortin like kinase 1; ddPCR: digital droplet polymerase chain reaction; DKK3: Dickkopf WNT signaling pathway inhibitor 3; DLEC1: deleted in lung and esophageal cancer 1;

DNA: dexoxyribonucleic acid; ECDC: UK Early Cancer Detection Consortium; 
EGFR: epidermal growth factor receptor (HER1); EP300: E1A binding protein P300; ERBB2: erb-B2 receptor tyrosine kinase 2 (HER2); ESR: estrogen receptor 1; FAM5C: BMP/retinoic acid inducible neural specific 3 (BRINP3); FDA: US Food and Drug Adminstration; FHIT: fragile histidine triad; FIT: faecal immunohistochemical testing; FoBT: faecal occult blood testing; GAPDH: glyceraldehyde-3-phosphate dehydrogenase; gCYC: cyclophilin A; GNA11: G protein subunit alpha 11; GNAQ: G protein subunit alpha Q; GPC3: glypican 3; GSTP1: glutathione S-transferase pi 1; HCC: hepatocellular carcinoma; HER1: human epidermal growth factor receptor 1; HER2: human epidermal growth factor receptor 2; HIC1: HIC ZBTB transcriptional repressor 1; HNSCC: head and neck squamous cell carcinoma; HOXA7: Homeobox A7; HOXA9: Homeobox A9; HOXD13: Homeobox D13; hTERT: human telomerase reverse transcriptase DNA; IgH: immunoglobulin heavy locus; INK4A: cyclin dependent kinase inhibitor 2A (CDKN2A/P16); ISO: International Standards Organization; ITIH5: inter-alpha-trypsin inhibitor heavy chain family member 5; KLK10: kallikrein related peptidase 10; KRAS: KRAS Proto-Oncogene, GTPase; LCH: Langerhans cell histocytosis; LINE1: long interspersed nuclear element 1 ; LoH: loss of heterozygosity; Max: maximum; MDG1: microvascular endothelial differentiation gene 1; MGMT: O(6)-methyl-guanine-DNA methyltransferase; Min: minimum; MLH1: MutL Homolog 1; mtDNA: mitochondrial DNA; MYC: MYC proto-oncogene; MYF3: myogenic differentiation 1 (MYOD1); MYLK: myosin light chain kinase; NGS: next generation sequencing; NICE: UK National Institute for Health and Care Excellence; NOS: not otherwise specified; OPCML: opioid binding protein/cell adhesion molecule like; P14: P14 ARF tumor suppressor protein gene; P16: P16 cyclin-dependent kinase inhibitor 2A (CDKN2A); P21: cyclin dependent kinase inhibitor 1A; P53: tumor protein P53; PCDH10: Protocadherin 10; PCDHGB7: protocadherin gamma subfamily B7; PCR: polymerase chain reaction;

PIK3CA: phosphatidylinositol-4,5-bisphosphate 3-kinase catalytic subunit alpha; PPIA: Peptidylprolyl isomerase A; PTGS2: Prostaglandin-endoperoxid synthase 2; qPCR: quantitative polymerase chain reaction; RARbeta2: Retinoid-acid-receptor-beta gene; RASSF1A: Ras association domain family member 1; RUNX3: runt related transcription factor 3; SFN: Stratifin; SFRP5: secreted frizzled related protein 5; SHOX2: short stature homeobox 2; SLC26A4: solute carrier family 26 member 4; SLC5A8: solute carrier family 5 member 8; SOX17: SRY-Box 17; SRBC: serum deprivation response factor-related gene; STARD: Standards for Reporting of Diagnostic Accuracy Studies; TAC1: tachykinin precursor 1; TFPI2: tissue factor pathway inhibitor 2; THBD-M: thrombomodulin; TIMP3: tissue inhibitor of metalloproteinase 3; TMS: tumor differentially expressed protein 1; UCHL1: Ubiquitin C-Terminal Hydrolase L1; V600E: Mutation resulting in an amino acid substitution at position 600 in BRAF, from a valine $(V)$ to a glutamic acid (E); VHL: Von Hippel Lindau gene; ZFP42: ZFP42 Zinc Finger Protein

\section{Acknowledgements}

We are grateful to the wider Early Cancer Detection Consortium for their assistance in putting together this paper, and for the many discussions which underpin it. Patient and Public representatives were involved in this work.

\section{Funding}

This work was conducted on behalf of the Early Cancer Detection Consortium, within the programme of work for work packages \& 2. The Early Cancer Detection Consortium is funded by Cancer Research UK under grant number: C50028/A18554. It was subsequently supported by an unrestricted educational grant from PinPoint Cancer Ltd. (www.pinpointcancer.co.uk), following cessation of the grant in 2016. Neither of the two funding bodies had any input or influence over the design, study, collection, analysis, or interpretation of the data.

\section{Availability of data and materials}

The papers quoted are publically available from the publishers, and many are now open access.

\section{Authors' contributions}

IC, SH, BW, and STP designed the study. Searches were performed by HBW. $\mathrm{LU}$ and HBW performed the mapping review with input from the ECDC. HK and IC scanned the resulting publications relating to ctDNA. The draft manuscript was prepared by IC with input fom MM, AC, DT, OS, AR, HK, HBW, BW and JS. All authors agreed the final version. All authors read and approved the final manuscript.

\section{Authors' information}

IC is a pathologist and has recently moved to a post with the International Agency for Research on Cancer of the World Health Organisation in Lyon. $\mathrm{LU}$, and $\mathrm{SH}$ are Research Fellows in systematic review and HBW is an Information Specialist working at the University of Sheffield, UK. HK is a scientist and PhD student working on early cancer detection. AR is a Lecturer in Biomedical Science working at Coventry University, UK. STP is an associate professor with a NIHR Career Development Fellowship using quantitative research methods to assess new screening programmes. MM is a healthcare scientist at the University of Leeds with expertise in biomarker and in vitro diagnostic (IVD) development, validation and clinical evaluation. AC is Professor of Cancer Genetic Epidemiology at the University of Sheffield, UK. DT is Reader in Epidemiology and Biostatistics at the University of Sheffield, UK. OS is Director of the Trinity Translational Medicine Institute (TTMI) and Professor in Molecular Pathology at Trinity College Dublin, Eire. JS is Professor of Translational Cancer Genetics at Leicester University, UK, with a particular interest in cfDNA.

\section{Ethics approval and consent to participate}

Not applicable.

\section{Consent for publication}

Not applicable.

\section{Competing interests}

The ECDC has grant funding for early cancer biomarker research from Cancer Research UK who funded this work. The ECDC involves several companies as follows: GE Healthcare, Life Technologies, NALIA Systems Ltd., and PerkinElmer. Individual ECDC members have declared their interests to the ECDC secretariat. IC was formerly chairman and CEO of PinPoint Cancer Ltd., a spin-out company from ECDC which in part funded the completion of this work though provision of staff time (IC). MM is supported by the National Institute for Health Research Diagnostic Evidence Co-operative Leeds. The views expressed are those of the author(s) and not necessarily those of the $\mathrm{NHS}$, the NIHR or the UK Department of Health.

\section{Publisher's Note}

Springer Nature remains neutral with regard to jurisdictional claims in published maps and institutional affiliations.

\section{Author details}

${ }^{1}$ WHO Classification of Tumours Group, International Agency for Research on Cancer (IARC), World Health Organization, 150 Cours Albert Thomas, 69372 Lyon, CEDEX 08, France. ${ }^{2}$ Faculty of Health and Life Sciences, Coventry University, Priory Street, Coventry CV1 5FB, UK. Institute of Ophthalmology, University College London, ECIV 9EL, London, UK. ${ }^{4}$ The School of Health and Related Research, The University of Sheffield, Regent Court, 30 Regent Street, Sheffield S1 4DA, UK. ${ }^{5}$ Department of Pathology, University Hospitals Coventry and Warwickshire, Coventry CV2 2DX, UK. ' London North West Healthcare NHS Trust, Northwick Park Hospital, Watford Road, Harrow HA1 3UJ, UK. 'Warwick Medical School, University of Warwick, Coventry CV4 7AL, UK. ${ }^{8}$ Leeds Centre for Personalised Medicine and Health, University of Leeds and NIHR Diagnostic Evidence Co-Operative Leeds, Leeds Teaching Hospitals NHS Trust, Leeds LS9 7TF, UK. 'Sheffield Institute for Nucleic Acids, Department of Oncology and Metabolism, The University of Sheffield, Medical School, Beech Hill Road, Sheffield S10 2RX, UK. ${ }^{10}$ Sir Patrick Dun Research Laboratory, Central Pathology Laboratory, St James's Hospital \& Trinity College Dublin, Dublin 8, Ireland. "'University of Leicester, Robert Kilpatrick Clinical Sciences Building, Leicester Royal Infirmary, Leicester LE2 7LX, UK.

Received: 8 March 2017 Accepted: 18 October 2017

Published online: 23 October 2017

\section{References}

1. McPhail S, et al. Stage at diagnosis and early mortality from cancer in England. Br J Cancer. 2015;112 Suppl 1:S108-15.

2. Duffy MJ. Tumor markers in clinical practice: a review focusing on common solid cancers. Med Princ Pract. 2013;22(1):4-11.

3. Hanahan D, Weinberg RA. Hallmarks of cancer: the next generation. Cell. 2011;144(5):646-74. 
4. Cree IA. Improved blood tests for cancer screening: general or specific? BMC Cancer. 2011;11:499.

5. Lo YM, et al. Presence of fetal DNA in maternal plasma and serum. Lancet. 1997;350(9076):485-7.

6. Johnson PJ, Lo YM. Plasma nucleic acids in the diagnosis and management of malignant disease. Clin Chem. 2002:48(8):1186-93.

7. Lou X, et al. A novel Alu-based real-time PCR method for the quantitative detection of plasma circulating cell-free DNA: sensitivity and specificity for the diagnosis of myocardial infarction. Int J Mol Med. 2015;35(1):72-80.

8. Swarup V, Rajeswari MR. Circulating (cell-free) nucleic acids-a promising, non-invasive tool for early detection of several human diseases. FEBS Lett. 2007:581(5):795-9.

9. Lo YM. Noninvasive prenatal diagnosis: from dream to reality. Clin Chem. 2015;61(1):32-7

10. Zonta E, Nizard P, Taly V. Assessment of DNA integrity, applications for cancer research. Adv Clin Chem. 2015;70:197-246.

11. Lo YM, et al. Maternal plasma DNA sequencing reveals the genome-wide genetic and mutational profile of the fetus. Sci Transl Med. 2010;2(61): 61 ra91.

12. Heitzer $E$, et al. Establishment of tumor-specific copy number alterations from plasma DNA of patients with cancer. Int J Cancer. 2013;133(2):346-56.

13. Uttley $L$, et al. Building the evidence base of blood-based biomarkers for early detection of cancer: a rapid systematic mapping review. EBioMedicine. 2016;10:164-73.

14. Page $K$, et al. Detection of HER2 amplification in circulating free DNA in patients with breast cancer. Br J Cancer. 2011;104(8):1342-8.

15. Kirkizlar $\mathrm{E}$, et al. Detection of clonal and subclonal copy-number variants in cell-free DNA from patients with breast cancer using a massively multiplexed PCR methodology. Transl Oncol. 2015;8(5):407-16.

16. Bettegowda $C$, et al. Detection of circulating tumor DNA in early- and latestage human malignancies. Sci Transl Med. 2014;6(224):224ra24.

17. Aung $\mathrm{KL}$, et al. Analytical validation of BRAF mutation testing from circulating free DNA using the amplification refractory mutation testing system. J Mol Diagn. 2014;16(3):343-9.

18. Board, R.E., et al., Detection of PIK3CA mutations in circulating free DNA in patients with breast cancer. Breast Cancer Res Treat, 2010. 120(2): p. 461-467.

19. Madhavan D, et al. Plasma DNA integrity as a biomarker for primary and metastatic breast cancer and potential marker for early diagnosis. Breast Cancer Res Treat. 2014;146(1):163-74.

20. Mead $\mathrm{R}$, et al. Circulating tumour markers can define patients with normal colons, benign polyps, and cancers. Br J Cancer. 2011;105(2):239-45.

21. Tabernero J, et al. Analysis of circulating DNA and protein biomarkers to predict the clinical activity of regorafenib and assess prognosis in patients with metastatic colorectal cancer: a retrospective, exploratory analysis of the CORRECT trial. Lancet Oncol. 2015;16(8):937-48.

22. Agostini $M$, et al. Circulating cell-free DNA: a promising marker of regional lymphonode metastasis in breast cancer patients. Cancer Biomark. 2012; 11(2-3):89-98.

23. Hao TB, et al. Circulating cell-free DNA in serum as a biomarker for diagnosis and prognostic prediction of colorectal cancer. Br J Cancer. 2014; 111(8):1482-9.

24. Zane $M$, et al. Circulating cell-free DNA, SLC5A8 and SLC26A4 hypermethylation, BRAF(V600E): a non-invasive tool panel for early detection of thyroid cancer. Biomed Pharmacother. 2013;67(8):723-30.

25. Sikora K, et al. Evaluation of cell-free DNA as a biomarker for pancreatic malignancies. Int J Biol Markers. 2014:e136-41.

26. Gong B, et al. Cell-free DNA in blood is a potential diagnostic biomarker of breast cancer. Oncol Lett. 2012;3(4):897-900.

27. Zhong XY, et al. Elevated level of cell-free plasma DNA is associated with breast cancer. Arch Gynecol Obstet. 2007;276(4):327-31.

28. Seefeld M, et al. Parallel assessment of circulatory cell-free DNA by PCR and nucleosomes by ELISA in breast tumors. Int J Biol Markers. 2008;23(2):69-73.

29. Zanetti-Dallenbach RA, et al. Levels of circulating cell-free serum DNA in benign and malignant breast lesions. Int J Biol Markers. 2007;22(2):95-9.

30. Perrone $F$, et al. Circulating free DNA in a screening program for early colorectal cancer detection. Tumori. 2014;100(2):115-21.

31. Divella $R$, et al. PAl-1, t-PA and circulating hTERT DNA as related to virus infection in liver carcinogenesis. Anticancer Res. 2008;28(1A):223-8.

32. Yang YJ, et al. Quantification of plasma hTERT DNA in hepatocellular carcinoma patients by quantitative fluorescent polymerase chain reaction. Clin Invest Med. 2011;34(4):E238.
33. Mazurek AM, et al. Assessment of the total cfDNA and HPV16/18 detection in plasma samples of head and neck squamous cell carcinoma patients. Oral Oncol. 2016;54:36-41.

34. Metz $\mathrm{CH}$, et al. Ultradeep sequencing detects GNAQ and GNA11 mutations in cell-free DNA from plasma of patients with uveal melanoma. Cancer Med. 2013;2(2):208-15.

35. Benesova $L$, et al. Mutation-based detection and monitoring of cell-free tumor DNA in peripheral blood of cancer patients. Anal Biochem. 2013; 433(2):227-34.

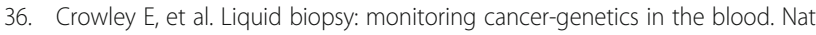
Rev Clin Oncol. 2013;10(8):472-84.

37. Salvi $\mathrm{S}$, et al. Cell-free DNA as a diagnostic marker for cancer: current insights. Onco Targets Ther. 2016;9:6549-59.

38. Cree IA, et al. Guidance for laboratories performing molecular pathology for cancer patients. J Clin Pathol. 2014;67(11):923-31.

39. Bossuyt PM, et al. STARD 2015: an updated list of essential items for reporting diagnostic accuracy studies. Clin Chem. 2015;61(12):1446-52.

40. Ladabaum U, et al. Colorectal cancer screening with blood-based biomarkers: cost-effectiveness of methylated septin 9 DNA versus current strategies. Cancer Epidemiol Biomark Prev. 2013;22(9):1567-76.

41. Heitzer E, Ulz P, Geigl JB. Circulating tumor DNA as a liquid biopsy for cancer. Clin Chem. 2015;61(1):112-23.

42. Kurihara $\mathrm{S}$, et al. Circulating free DNA as non-invasive diagnostic biomarker for childhood solid tumors. J Pediatr Surg. 2015;50(12):2094-7.

43. Kurtz DM, et al. Noninvasive monitoring of diffuse large B-cell lymphoma by immunoglobulin high-throughput sequencing. Blood. 2015;125(24):3679-87.

44. Newman AM, et al. An ultrasensitive method for quantitating circulating tumor DNA with broad patient coverage. Nat Med. 2014;20(5):548-54.

45. Belic J, et al. Rapid identification of plasma DNA samples with increased ctDNA levels by a modified FAST-SeqS approach. Clin Chem. 2015;61(6): 838-49.

46. Andersen RF, et al. Improved sensitivity of circulating tumor DNA measurement using short PCR amplicons. Clin Chim Acta. 2015;439:97-101.

47. Ellinger J, et al. CpG island hypermethylation of cell-free circulating serum DNA in patients with testicular cancer. J Urol. 2009;182(1):324-9.

48. Martinez-Galan J, et al. Quantitative detection of methylated ESR1 and 14-33-sigma gene promoters in serum as candidate biomarkers for diagnosis of breast cancer and evaluation of treatment efficacy. Cancer Biol Ther. 2008; 7(6):958-65.

49. Kristensen $\mathrm{LS}$, et al. Methylation profiling of normal individuals reveals mosaic promoter methylation of cancer-associated genes. Oncotarget. 2012; 3(4):450-61.

50. Page $K$, et al. Influence of plasma processing on recovery and analysis of circulating nucleic acids. PLoS One. 2013;8(10):e77963.

51. Sorber $L$, et al. A comparison of cell-free DNA isolation kits: isolation and quantification of cell-free DNA in plasma. J Mol Diagn. 2017;19(1):162-8.

52. De Mattos-Arruda L, et al. Cerebrospinal fluid-derived circulating tumour DNA better represents the genomic alterations of brain tumours than plasma. Nat Commun. 2015;6:8839.

53. Taback B, Saha S, Hoon DS. Comparative analysis of mesenteric and peripheral blood circulating tumor DNA in colorectal cancer patients. Ann N Y Acad Sci. 2006;1075:197-203.

54. Uchida J, et al. Diagnostic accuracy of noninvasive genotyping of EGFR in lung cancer patients by deep sequencing of plasma cell-free DNA. Clin Chem. 2015;61(9):1191-6.

55. Fernandez-Cuesta $L$, et al. Identification of circulating tumor DNA for the early detection of small-cell lung cancer. EBioMedicine. 2016;10:117-23.

56. Warton K, Samimi G. Methylation of cell-free circulating DNA in the diagnosis of cancer. Front Mol Biosci. 2015;2:13.

57. Payne SR. From discovery to the clinic: the novel DNA methylation biomarker (m)SEPT9 for the detection of colorectal cancer in blood. Epigenomics. 2010;2(4):575-85.

58. Church TR, et al. Prospective evaluation of methylated SEPT9 in plasma for detection of asymptomatic colorectal cancer. Gut. 2014;63(2):317-25.

59. Potter NT, et al. Validation of a real-time PCR-based qualitative assay for the detection of methylated SEPT9 DNA in human plasma. Clin Chem. 2014; 60(9):1183-91.

60. Toth $\mathrm{K}$, et al. Circadian rhythm of methylated Septin 9, cell-free DNA amount and tumor markers in colorectal cancer patients. Pathol Oncol Res. 2016;

61. Zhao QT, et al. Diagnostic value of SHOX2 DNA methylation in lung cancer: a meta-analysis. Onco Targets Ther. 2015;8:3433-9. 
62. Begum S, et al. An epigenetic marker panel for detection of lung cancer using cell-free serum DNA. Clin Cancer Res. 2011;17(13):4494-503.

63. Yi JM, et al. Novel methylation biomarker panel for the early detection of pancreatic cancer. Clin Cancer Res. 2013;19(23):6544-55.

64. Diehl $F$, et al. Detection and quantification of mutations in the plasma of patients with colorectal tumors. Proc Natl Acad Sci U S A. 2005;102(45): 16368-73.

65. Lin JK, et al. Clinical relevance of alterations in quantity and quality of plasma DNA in colorectal cancer patients: based on the mutation spectra detected in primary tumors. Ann Surg Oncol, 201421 Suppl. 4:S680-6.

66. Wang JY, et al. Molecular detection of APC, K- ras, and p53 mutations in the serum of colorectal cancer patients as circulating biomarkers. World J Surg. 2004;28(7):721-6.

67. Zhang $\mathrm{Q}$, et al. A multiplex methylation-specific PCR assay for the detection of early-stage ovarian cancer using cell-free serum DNA. Gynecol Oncol. 2013;130(1):132-9.

68. Hauser $\mathrm{S}$, et al. Serum DNA hypermethylation in patients with kidney cancer: results of a prospective study. Anticancer Res. 2013;33(10):4651-6.

69. Radpour R, et al. Hypermethylation of tumor suppressor genes involved in critical regulatory pathways for developing a blood-based test in breast cancer. PLoS One. 2011;6(1):e16080.

70. Zhang $Y$, et al. Methylation of multiple genes as a candidate biomarker in non-small cell lung cancer. Cancer Lett. 2011;303(1):21-8.

71. Skrypkina I, et al. Concentration and methylation of cell-free DNA from blood plasma as diagnostic markers of renal cancer. Dis Markers. 2016;2016: 3693096.

72. Pack SC, et al. Usefulness of plasma epigenetic changes of five major genes involved in the pathogenesis of colorectal cancer. Int J Color Dis. 2013;28(1): 139-47.

73. Sikora $\mathrm{K}$, et al. Evaluation of cell-free DNA as a biomarker for pancreatic malignancies. Int J Biol Markers. 2015;30(1):e136-41.

74. Hsu HS, et al. Characterization of a multiple epigenetic marker panel for lung cancer detection and risk assessment in plasma. Cancer. 2007;110(9): 2019-26.

75. Couraud S, et al. Noninvasive diagnosis of actionable mutations by deep sequencing of circulating free DNA in lung cancer from never-smokers: a proof-of-concept study from BioCAST/IFCT-1002. Clin Cancer Res. 2014; 20(17):4613-24.

76. Hyman DM, et al. Prospective blinded study of BRAFV600E mutation detection in cell-free DNA of patients with systemic histiocytic disorders. Cancer Discov. 2015;5(1):64-71.

77. Thierry AR, et al. Clinical validation of the detection of KRAS and BRAF mutations from circulating tumor DNA. Nat Med. 2014;20(4):430-5.

78. Kim BH, et al. Detection of plasma BRAF(V600E) mutation is associated with lung metastasis in papillary thyroid carcinomas. Yonsei Med J. 2015;56(3):634-40.

79. Sharma G, et al. Clinical significance of promoter hypermethylation of DNA repair genes in tumor and serum DNA in invasive ductal breast carcinoma patients. Life Sci. 2010;87(3-4):83-91.

80. Ibanez de Caceres I, et al. Tumor cell-specific BRCA1 and RASSF1A hypermethylation in serum, plasma, and peritoneal fluid from ovarian cancer patients. Cancer Res. 2004;64(18):6476-81.

81. Melnikov A, et al. Differential methylation profile of ovarian cancer in tissues and plasma. J Mol Diagn. 2009;11(1):60-5.

82. Liggett, T.E., et al., Distinctive DNA methylation patterns of cell-free plasma DNA in women with malignant ovarian tumors. Gynecol Oncol, 2011. 120(1): p. 113-20.

83. Hulbert A, et al. Early detection of lung cancer using DNA promoter Hypermethylation in plasma and sputum. Clin Cancer Res. 2016;

84. Chimonidou M, et al. CST6 promoter methylation in circulating cell-free DNA of breast cancer patients. Clin Biochem. 2013;46(3):235-40.

85. Chen L, et al. Hypermethylated FAM5C and MYLK in serum as diagnosis and pre-warning markers for gastric cancer. Dis Markers. 2012;32(3):195-202.

86. Melson J, et al. Commonality and differences of methylation signatures in the plasma of patients with pancreatic cancer and colorectal cancer. Int J Cancer. 2014;134(11):2656-62.

87. Tian F, et al. Promoter hypermethylation of tumor suppressor genes in serum as potential biomarker for the diagnosis of nasopharyngeal carcinoma. Cancer Epidemiol. 2013;37(5):708-13.

88. Powrozek T, et al. Methylation of the DCLK1 promoter region in circulating free DNA and its prognostic value in lung cancer patients. Clin Transl Oncol. 2015;
89. Powrozek T, et al. Methylation of the DCLK1 promoter region in circulating free DNA and its prognostic value in lung cancer patients. Clin Transl Oncol. 2016;18(4):398-404.

90. Kloten $\mathrm{V}$, et al. Promoter hypermethylation of the tumor-suppressor genes ITIH5, DKK3, and RASSF1A as novel biomarkers for blood-based breast cancer screening. Breast Cancer Res. 2013;15(1):R4.

91. Chiappetta $C$, et al. Use of a new generation of capillary electrophoresis to quantify circulating free DNA in non-small cell lung cancer. Clin Chim Acta. 2013;425:93-6.

92. Szpechcinski A, et al. Plasma cell-free DNA levels and integrity in patients with chest radiological findings: NSCLC versus benign lung nodules. Cancer Lett. 2016;374(2):202-7.

93. Shao $X$, et al. Quantitative analysis of cell-free DNA in ovarian cancer. Oncol Lett. 2015;10(6):3478-82.

94. Andolfo I, et al. Detection of erbB2 copy number variations in plasma of patients with esophageal carcinoma. BMC Cancer. 2011;11:126.

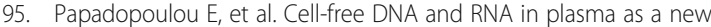
molecular marker for prostate and breast cancer. Ann N Y Acad Sci. 2006; 1075:235-43.

96. Dumache $\mathrm{R}$, et al. Prostate cancer molecular detection in plasma samples by glutathione S-transferase P1 (GSTP1) methylation analysis. Clin Lab. 2014; 60(5):847-52.

97. Minciu $R$, et al. Molecular diagnostic of prostate cancer from body fluids using methylation-specific PCR (MS-PCR) method. Clin Lab. 2016;62(6):1183-6.

98. Cassinotti $E$, et al. DNA methylation patterns in blood of patients with colorectal cancer and adenomatous colorectal polyps. Int J Cancer. 2012; 131(5):1153-7.

99. Shan $\mathrm{M}$, et al. Detection of aberrant methylation of a six-gene panel in serum DNA for diagnosis of breast cancer. Oncotarget. 2016;7(14):18485-94.

100. Huang $\mathrm{G}$, et al. Evaluation of INK4A promoter methylation using pyrosequencing and circulating cell-free DNA from patients with hepatocellular carcinoma. Clin Chem Lab Med. 2014;52(6):899-909.

101. Kuo YB, et al. Comparison of KRAS mutation analysis of primary tumors and matched circulating cell-free DNA in plasmas of patients with colorectal cancer. Clin Chim Acta. 2014;433:284-9.

102. Spindler $\mathrm{KL}$, et al. Circulating free DNA as biomarker and source for mutation detection in metastatic colorectal cancer. PLoS One. 2015;10(4): e0108247.

103. Freidin MB, et al. Circulating tumor DNA outperforms circulating tumor cells for KRAS mutation detection in thoracic malignancies. Clin Chem. 2015; 61(10):1299-304.

104. Sozzi G, et al. Detection of microsatellite alterations in plasma DNA of nonsmall cell lung cancer patients: a prospect for early diagnosis. Clin Cancer Res. 1999;5(10):2689-92.

105. Eisenberger CF, et al. The detection of oesophageal adenocarcinoma by serum microsatellite analysis. Eur J Surg Oncol. 2006;32(9):954-60.

106. Castagnaro A, et al. Microsatellite analysis of induced sputum DNA in patients with lung cancer in heavy smokers and in healthy subjects. Exp Lung Res. 2007;33(6):289-301.

107. Andriani F, et al. Detecting lung cancer in plasma with the use of multiple genetic markers. Int J Cancer. 2004;108(1):91-6.

108. Xia P, et al. Decreased mitochondrial DNA content in blood samples of patients with stage I breast cancer. BMC Cancer. 2009;9:454.

109. Kadam SK, Farmen M, Brandt JT. Quantitative measurement of cell-free plasma DNA and applications for detecting tumor genetic variation and promoter methylation in a clinical setting. J Mol Diagn. 2012;14(4):346-56.

110. Zaher ER, et al. Cell-free DNA concentration and integrity as a screening tool for cancer. Indian J Cancer. 2013;50(3):175-83.

111. Danese $E$, et al. Epigenetic alteration: new insights moving from tissue to plasma - the example of PCDH10 promoter methylation in colorectal cancer. Br J Cancer. 2013;109(3):807-13.

112. Skvortsova TE, et al. Cell-free and cell-bound circulating DNA in breast tumours: DNA quantification and analysis of tumour-related gene methylation. Br J Cancer. 2006;94(10):1492-5.

113. Hoque MO, et al. Detection of aberrant methylation of four genes in plasma DNA for the detection of breast cancer. J Clin Oncol. 2006;24(26):4262-9.

114. Salvianti F, et al. Tumor-related methylated cell-free DNA and circulating tumor cells in melanoma. Front Mol Biosci. 2015;2:76.

115. Rykova EY, et al. Investigation of tumor-derived extracellular DNA in blood of cancer patients by methylation-specific PCR. Nucleosides Nucleotides Nucleic Acids. 2004;23(6-7):855-9. 
116. Mohamed NA, et al. Is serum level of methylated RASSF1A valuable in diagnosing hepatocellular carcinoma in patients with chronic viral hepatitis C? Arab J Gastroenterol. 2012;13(3):111-5.

117. Zhang YJ, et al. Predicting hepatocellular carcinoma by detection of aberrant promoter methylation in serum DNA. Clin Cancer Res. 2007;13(8): 2378-84.

118. de Martino M, et al. Serum cell-free DNA in renal cell carcinoma: a diagnostic and prognostic marker. Cancer. 2012;118(1):82-90.

119. deVos T, et al. Circulating methylated SEPT9 DNA in plasma is a biomarker for colorectal cancer. Clin Chem. 2009;55(7):1337-46.

120. Grutzmann R, et al. Sensitive detection of colorectal cancer in peripheral blood by septin 9 DNA methylation assay. PLoS One. 2008;3(11):e3759.

121. Toth $\mathrm{K}$, et al. Detection of methylated septin 9 in tissue and plasma of colorectal patients with neoplasia and the relationship to the amount of circulating cell-free DNA. PLoS One. 2014:9(12):e115415.

122. Powrozek T, et al. Septin 9 promoter region methylation in free circulating DNA-potential role in noninvasive diagnosis of lung cancer: preliminary report. Med Oncol. 2014;31(4):917.

123. Jin $\mathrm{P}$, et al. Performance of a second-generation methylated SEPT9 test in detecting colorectal neoplasm. J Gastroenterol Hepatol. 2015;30(5):830-3.

124. Warren JD, et al. Septin 9 methylated DNA is a sensitive and specific blood test for colorectal cancer. BMC Med. 2011:9:133.

125. Kneip C, et al. SHOX2 DNA methylation is a biomarker for the diagnosis of lung cancer in plasma. J Thorac Oncol. 2011;6(10):1632-8.

126. Weiss $\mathrm{G}$, et al. Validation of the SHOX2/PTGER4 DNA methylation marker panel for plasma-based discrimination between patients with malignant and nonmalignant lung disease. J Thorac Oncol. 2017;12(1):77-84.

127. Chimonidou M, et al. SOX17 promoter methylation in circulating tumor cells and matched cell-free DNA isolated from plasma of patients with breast cancer. Clin Chem. 2013;59(1):270-9.

128. Lange CP, et al. Genome-scale discovery of DNA-methylation biomarkers for blood-based detection of colorectal cancer. PLoS One. 2012;7(11):e50266.

\section{Submit your next manuscript to BioMed Central and we will help you at every step:}

- We accept pre-submission inquiries

- Our selector tool helps you to find the most relevant journal

- We provide round the clock customer support

- Convenient online submission

- Thorough peer review

- Inclusion in PubMed and all major indexing services

- Maximum visibility for your research

Submit your manuscript at www.biomedcentral.com/submit

) Biomed Central 